\title{
Erratum to: Closed form solution for a conductive-convective- radiative annular fin with multiple nonlinearities and its inverse analysis
}

\author{
Rajiv Ranjan ${ }^{1} \cdot$ Ashis Mallick $^{1} \cdot$ Dilip K. Prasad $^{2}$
}

Published online: 7 September 2016

C) Springer-Verlag Berlin Heidelberg 2016

\section{Erratum to: Heat Mass Transfer DOI 10.1007/s00231-016-1872-8}

The original publication of the article has been updated to reflect these changes.

In the original publication of the article, the following mistakes have been identified.

1. The 'second last term' in the RHS of Eq. (8) should contain a 'plus (+)' sign between 1 and lambda $\left(\lambda_{R}\right)$. Accordingly, the correct form of Eq. 8 is

$$
\begin{aligned}
L(\theta) & +p L\left(\theta_{o}\right)-L\left(\theta_{o}\right) \\
= & -p\left[\beta \theta \frac{d^{2} \theta}{d \xi^{2}}+\beta_{1} \theta^{2} \frac{d^{2} \theta}{d \xi^{2}}+\beta\left(\frac{d \theta}{d \xi}\right)^{2}\right. \\
& +2 \beta_{1} \theta\left(\frac{d \theta}{d \xi}\right)^{2}+\frac{1}{1+\xi} \frac{d \theta}{d \xi} \\
& +\frac{\beta \theta}{1+\xi} \frac{d \theta}{d \xi}+\frac{\beta_{1}}{1+\xi} \theta^{2} \frac{d \theta}{d \xi}-N^{2} \theta^{n+1} \\
& \left.-M \theta^{4}\left(1+\lambda_{R} \theta\right)+G\left(1+E_{G} \theta\right)\right]
\end{aligned}
$$

2. In Eq. (10), the equation for $p^{1}$ has been repeated twice by mistake.

The online version of the original article can be found under doi:10.1007/s00231-016-1872-8.

\section{Ashis Mallick}

mal123_us@yahoo.com

1 Department of Mechanical Engineering, Indian School of Mines, Dhanbad 826 004, India

2 Computational Intelligence Graduate Lab, Nanyang Technological University, Singapore 639798, Singapore 